\title{
A Carpenter's Rainbow
}

\section{Julie Kitzenberger}

My Dad was anything to do with building: carpentry, construction, design, and specialty kitchen cabinetry. He built freeways, parking lots, bank lobbies, museums, restaurants, office buildings, and remodeled kitchens. He was a carpenter, true and true.

Although he and my Mom had not been married for over 50 years, they had always remained friendly. When he passed away, my step-mother fell into a deep depression and said she was not up to having his memorial.

'Your father deserves a Celebration of Life,' my Mom said. We held the gathering in her back yard.

It was a sunny day, full of blue sky and lots of light. There was a wooden bench that circled an enormous Cypress tree. Folks helped me lift my Dad's carpenter toolbox onto the bench for all to admire. He had built it with the precision his work was known for. It had 7 drawers. Each was for a specific type of tool, with wooden pieces built in to section out where the various tools of his trade belonged. There was a door that shut in front of all the drawers, with a lock. Whenever he worked on a job, he would load the toolbox into his SUV, drive it to the construction site, and chain it to something so nothing could be stolen.

On top of the toolbox I placed the award I made for my Dad the year before. It said he had been inducted into the Master Builders Hall of Fame. It had a San Francisco Giants baseball World Series trophy with one photo of my Dad welding something while wearing his safety glasses and another of him smiling, a photo I called, 'My Dad, Always Laughing.'

We played my Dad's favorite song, 'If I Were a Carpenter,' ${ }^{1}$ throughout the afternoon. Johnny Cash sang it to his wife, June Carter Cash, asking if she, a lady, would still marry him if he were only a carpenter. It wasn't outdated; it was a classic. Some had pressured my Dad to stop doing what he loved to become a contractor, but he wouldn't abandon his chosen occupation to make more money. Johnny represented the working man. So did my Dad.

My Dad's preferred hammer was a 13-ounce claw hammer with a hickory wood handle. Peter, Paul and Mary's song, 'If I Had a Hammer,'2 was another of his favorites, which we also played. My Dad cared deeply about the welfare of others. In the song, the hammer represents justice and the lyrics speak of love for community 'all over this land.'

Those who loved my Dad from all walks of his carpenter's life were there. Workers from the local carpenters' union. His former students and staff from the city's Building Education Center, where he taught carpentry to homeowners on evenings and weekends for over 30 years. Co-workers from the local Ace Hardware, where he had worked after retirement, providing carpentry advice until a few months before his passing. And clients who had become friends were there to share stories of the remodeling work he had done for their homes.

\footnotetext{
${ }^{1}$ https://www.youtube.com/watch?v=MSQ6fSKLIG0

2 https://www.youtube.com/watch?v=JD-pyWALro4
} 
During the service, we watched for rainbows, which my Dad loved. Two days later, I loaded my car with my Dad's things from the memorial to take home with me: his toolbox, his award, his framed photo and his cap from the Building Education Center. As I walked down the steps from my Mom's porch, we looked west into the blue sky and noticed many white clouds. The sky was usually all blue, but this day there were pillow-sized clouds everywhere.

We noticed a rainbow shining across one cloud hovering high over a palm tree. Then we noticed a second rainbow shining across a second cloud, just as high up, and somewhat to the left. I've never seen that before or since.

My Mom smiled. 'Your Dad sent a rainbow for each of us.'

\section{Author Bio}

Julie Kitzenberger is an emerging writer who shares her passions for cats, wildlife, ranching and the surprises of daily life through both her writing and her photography. Her writing guides her photo capture; her image prospecting often inspires her stories. Julie won national awards for her first two pieces published. Her cover story for Western Horseman, "A 125Year Tradition," won Best Freelance Writer in Equine Journalism. Her feature story for Modern Arabian Horse magazine, "A Lady Rancher with the Right Stuff," won Best Feature Story and Best Editorial Photo in Equine Media. These stories can be read on the Tearsheets page of her website, www.JulieKitzenberger.com. Recent flash fiction favorites can be found on her blog, juliekblog.com. Julie has a B.F.A. from New York University's School of the Arts and a B.S. in Computer Science from Rutgers University. Julie lives in the San Francisco Bay Area where she trains and photographs her amazing cat, Coco. 
\#1 - My Dad's award, 'Master Builders Hall of Fame':

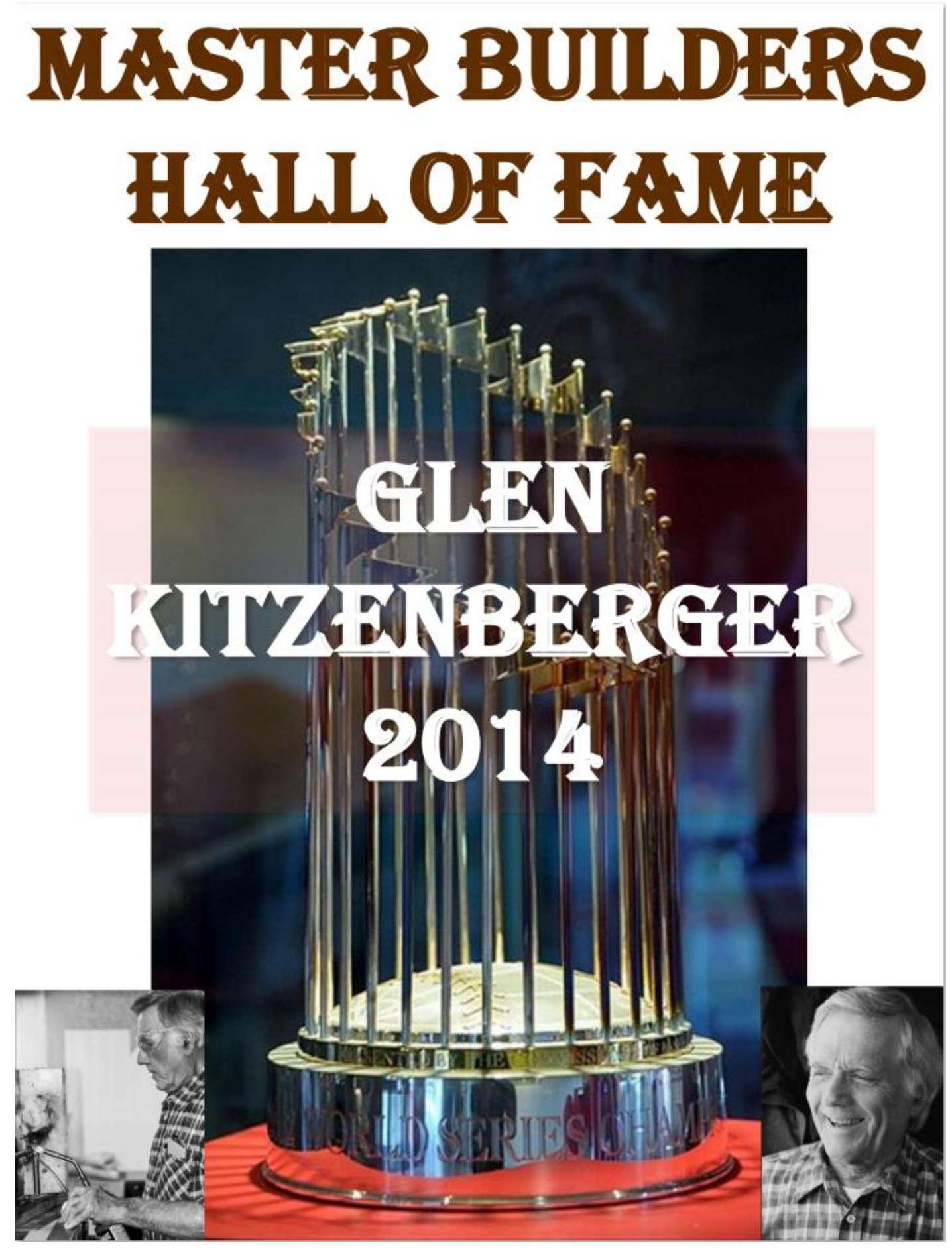


\#2 - Two views of my Dad's hand-made toolbox:

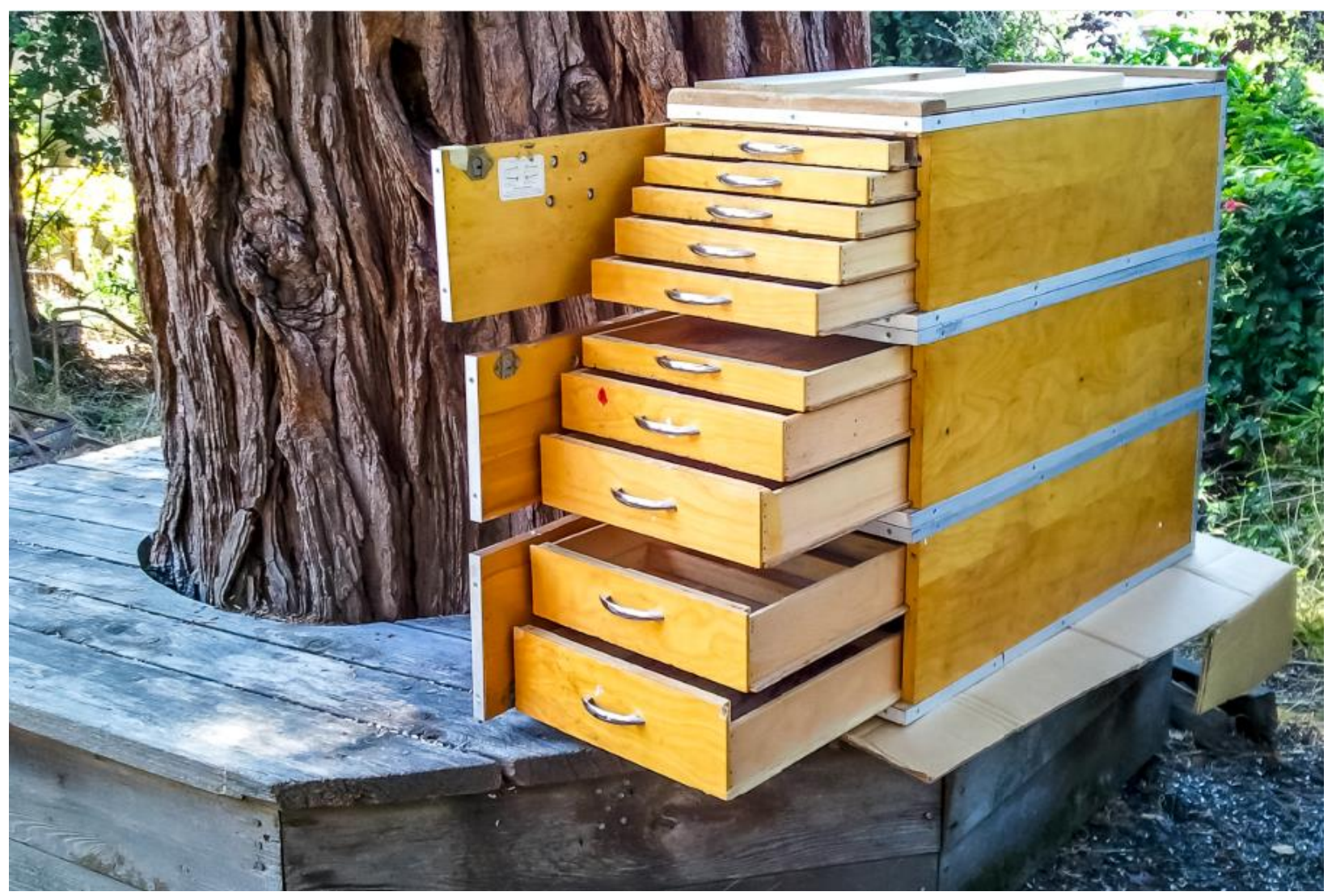


\#3 - Toolbox

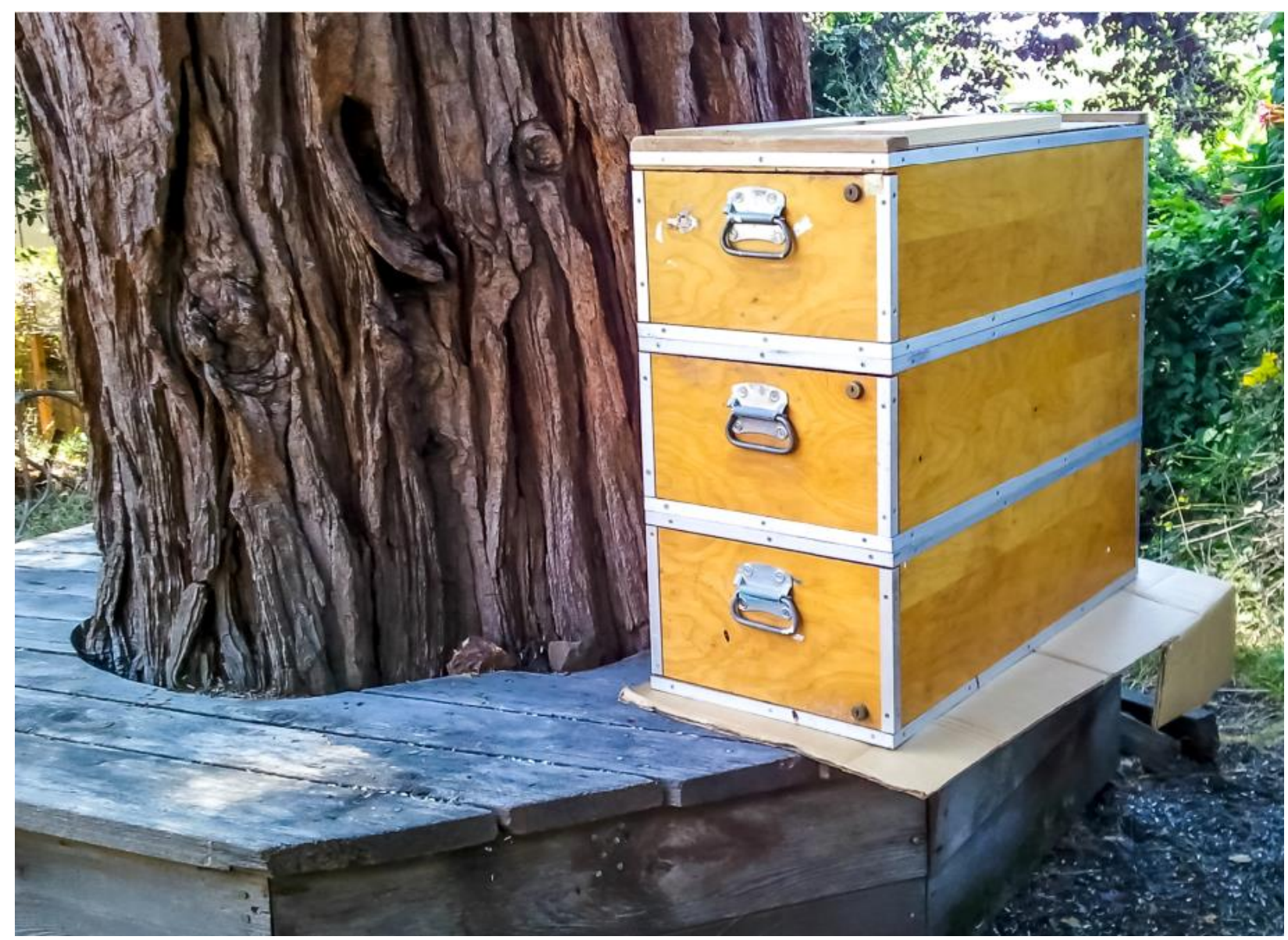


\#4 - My Dad's toolbox with his cap from the Building Education Center and the photo of him always laughing.

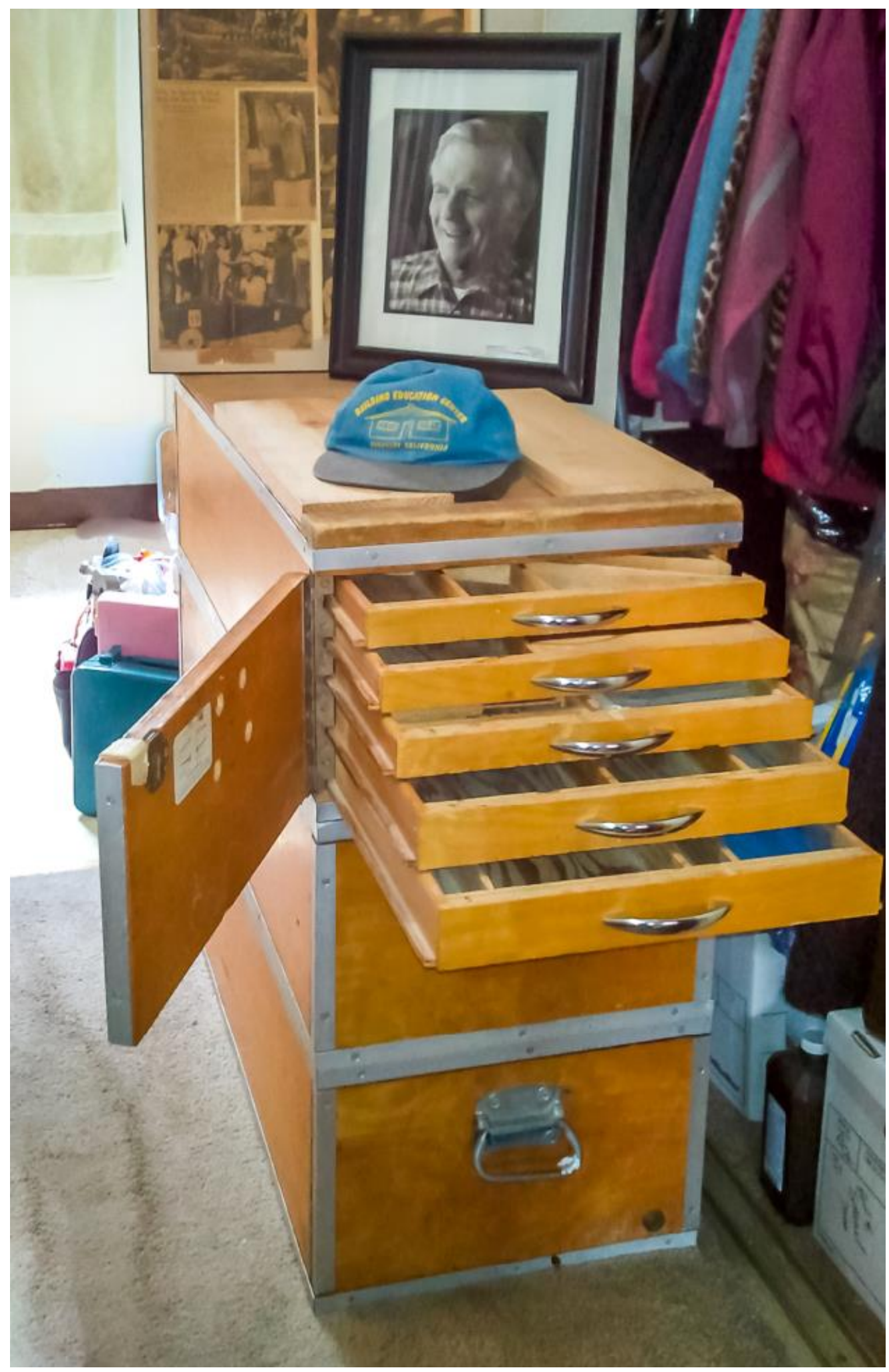




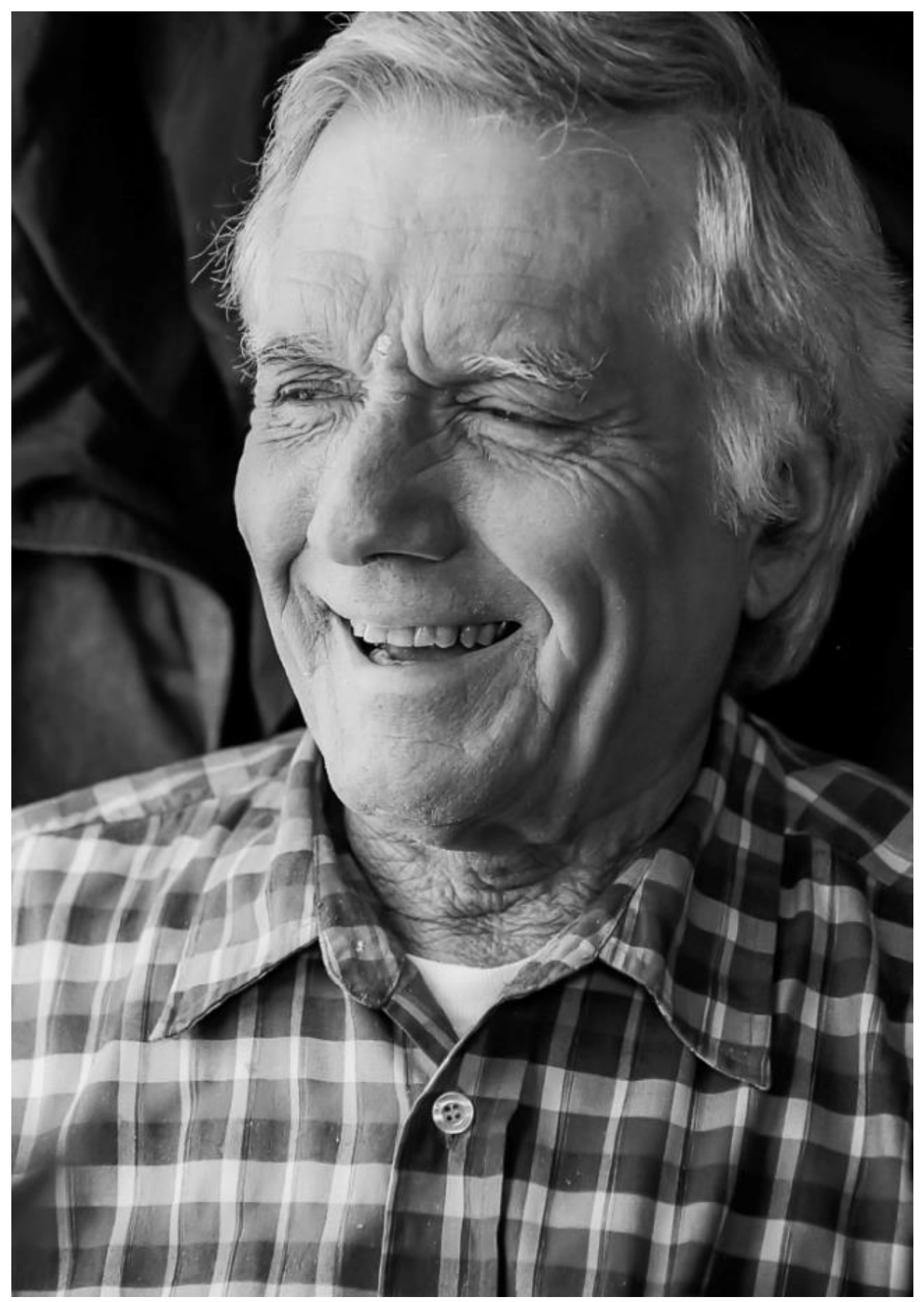

\#5 - 'My Dad, Always Laughing' 
\#6 - My Dad in his carpentry clothes in the 1970s:

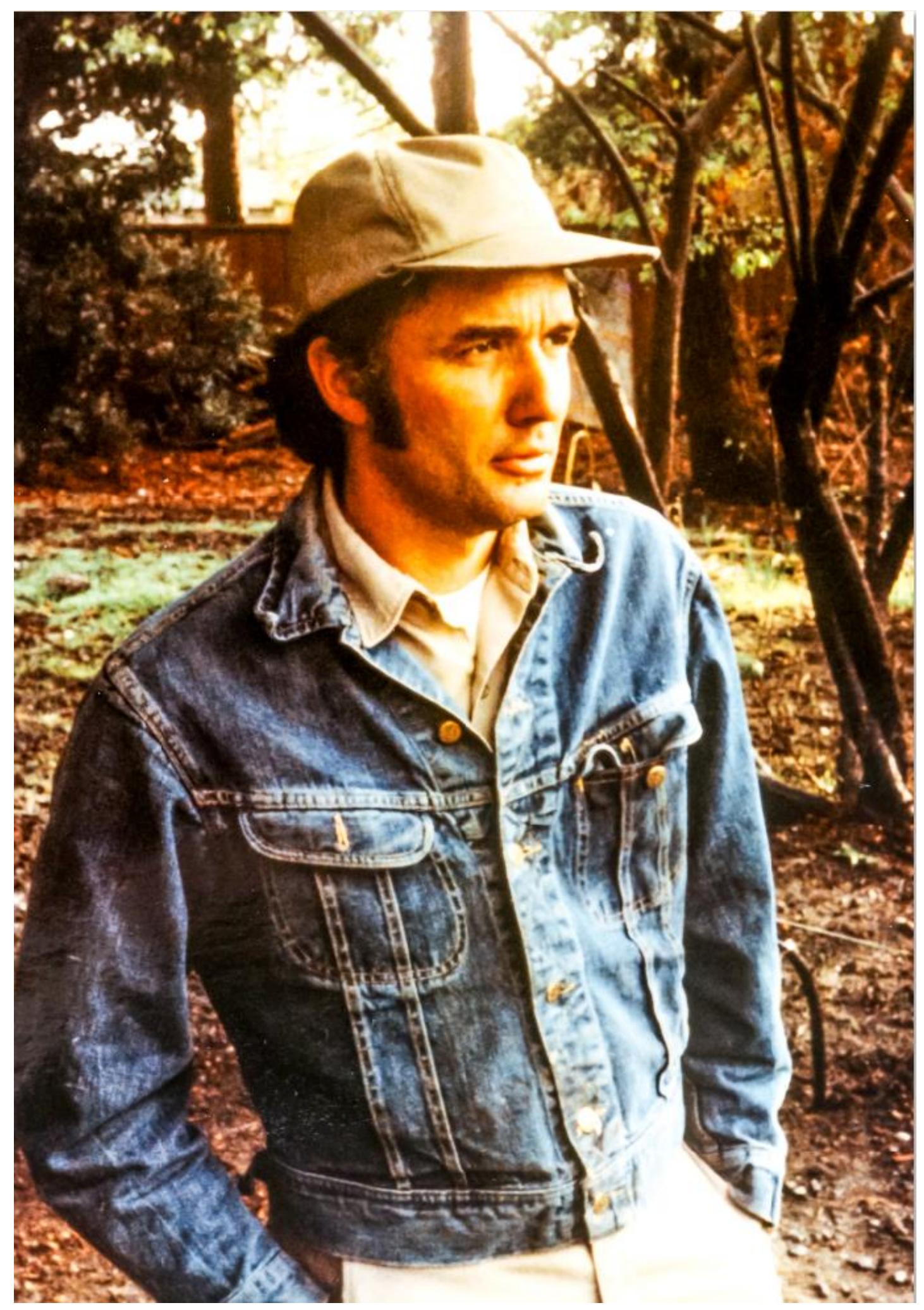


\#7 - My Dad teaching welding at the Building Education Center where he taught carpentry to homeowners for over 30 years.

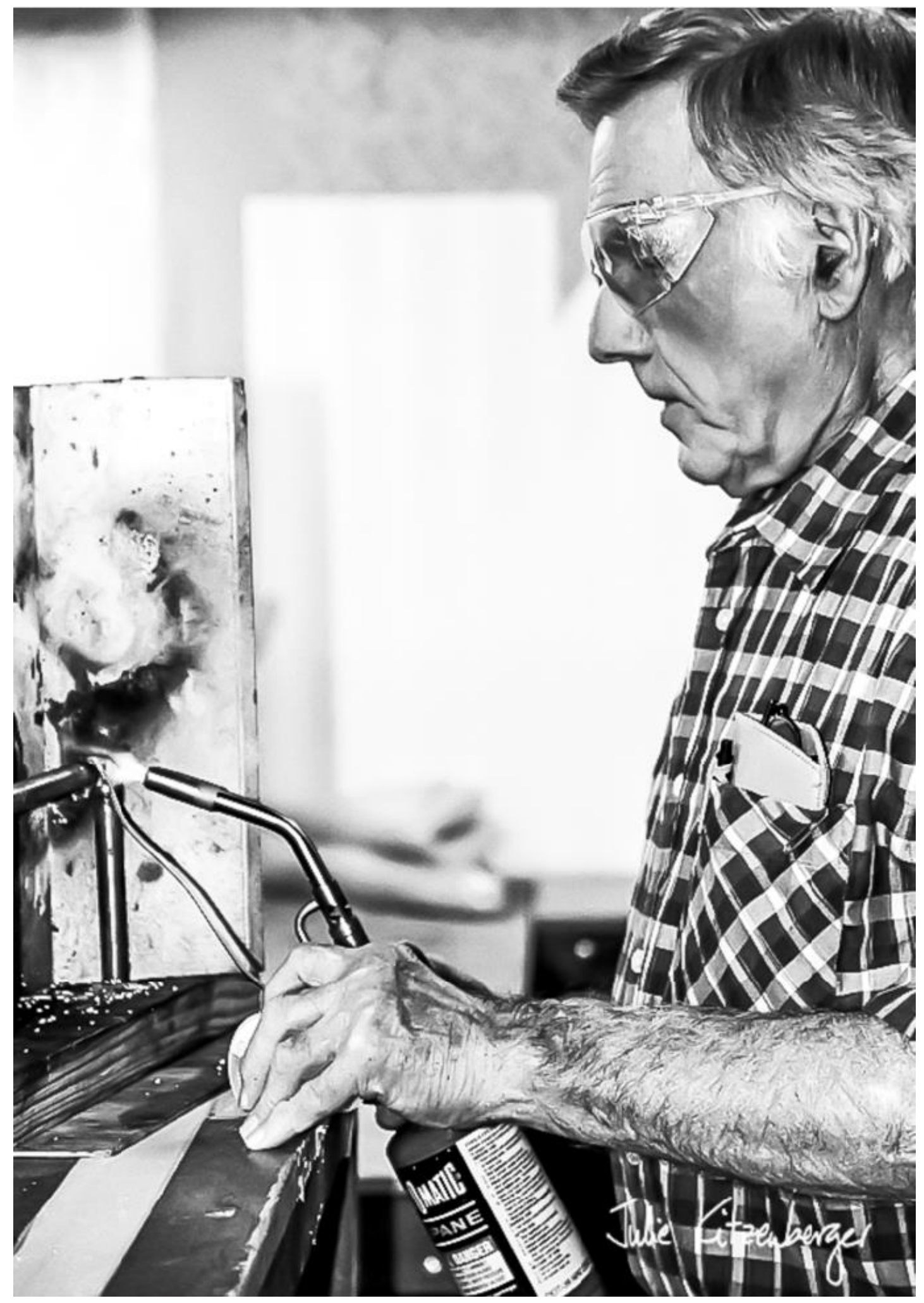


\#8 - After retirement, my Dad worked at the local Ace Hardware, giving carpentry advice to customers until a few months before he died.

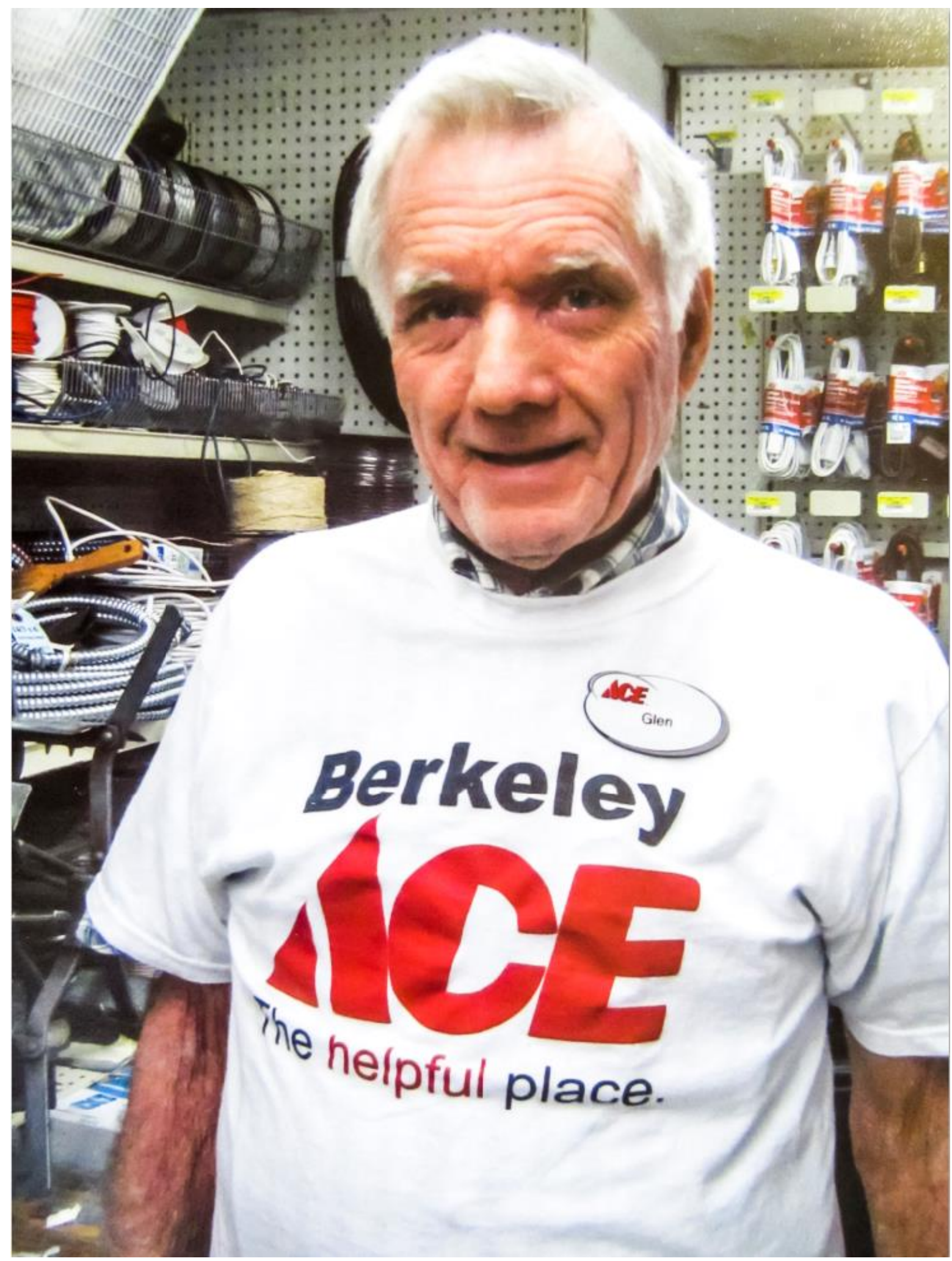

